\title{
Recent advances in vertebrate and invertebrate transgenerational immunity in the light of ecology and evolution
}

\author{
Olivia Roth $\mathbb{1}^{1} \cdot$ Anne Beemelmanns $s^{1,2} \cdot$ Seth M. Barribeau ${ }^{3} \cdot$ Ben M. Sadd ${ }^{4}$
}

Received: 15 November 2017 / Revised: 6 May 2018 / Accepted: 31 May 2018 / Published online: 18 June 2018

(c) The Genetics Society 2018

\begin{abstract}
Parental experience with parasites and pathogens can lead to increased offspring resistance to infection, through a process known as transgenerational immune priming (TGIP). Broadly defined, TGIP occurs across a wide range of taxa, and can be viewed as a type of phenotypic plasticity, with hosts responding to the pressures of relevant local infection risk by altering their offspring's immune defenses. There are ever increasing examples of both invertebrate and vertebrate TGIP, which go beyond classical examples of maternal antibody transfer. Here we critically summarize the current evidence for TGIP in both invertebrates and vertebrates. Mechanisms underlying TGIP remain elusive in many systems, but while it is unlikely that they are conserved across the range of organisms with TGIP, recent insight into epigenetic modulation may challenge this view. We place TGIP into a framework of evolutionary ecology, discussing costs and relevant environmental variation. We highlight how the ecology of species or populations should affect if, where, when, and how TGIP is realized. We propose that the field can progress by incorporating evolutionary ecology focused designs to the study of the so far well chronicled, but mostly descriptive TGIP, and how rapidly developing -omic methods can be employed to further understand TGIP across taxa.
\end{abstract}

\section{Parental effects and transgenerational immune priming}

The genotype of an offspring is determined by the merging of maternal and paternal DNA, but the offspring's phenotype is influenced by a plethora of environmental factors, which provide enormous plasticity (Bonduriansky and Day 2009; Bonduriansky 2012; Scheiner 2014). Parental effects represent one form of phenotypic plasticity across generations, where inherited environmental effects can be transferred to offspring from mothers and fathers (Kirkpatrick

Olivia Roth

oroth@geomar.de

1 Marine Ecology, GEOMAR Helmholtz Centre for Ocean Research Kiel, Düsternbrookerweg 20, 24105 Kiel, Germany

2 Department of Ocean Sciences, Memorial University of Newfoundland, 0 Marine Lab Rd, St. John's, NL, Canada

3 Institute of Integrative Biology, University of Liverpool, Crown Street, Liverpool L69 7ZB, UK

4 School of Biological Sciences, Illinois State University, Normal, IL 61790-4120, USA and Lande 1989; Rossiter 1996; Mousseau and Fox 1998). Traditionally, paternal effects were thought to be rare due to both evolutionary and mechanistic constraints (Kokko and Jennions 2008; Crean and Bonduriansky 2014). However, a number of recent examples suggested they might be more prevalent (Heijmans et al. 2008; Carone et al. 2010; Rando 2012; Roth et al. 2012; Crean et al. 2013; Jiang et al. 2013; Crean and Bonduriansky 2014; Eggert et al. 2014; Kaufmann et al. 2014; Stein and Bell 2014). Thus, while mechanistic constraints may exist, in sexually reproducing species both maternal and paternal effects have the potential to mediate offspring phenotype.

Parental effects are responsible for a broad range of plastic responses across generations, e.g. predator defenses (Agrawal et al. 1999), acclimation to abiotic environmental changes (Donelson et al. 2012; Sunday et al. 2012; Shama and Wegner 2014; Roth and Landis 2017), and disease resistance (Mitchell and Read 2005; Goellner and Conrath 2008). Transgenerational immune priming (TGIP), where parents enhance offspring immune defense based on their own immunological experience, can thus be viewed as a case of phenotypic plasticity achieved through parental effects (Grindstaff et al. 2003; Moret 2006; Hasselquist and Nilsson 2009; Moreau et al. 2012; Roth et al. 2012). 
Here we present and discuss current evidence for TGIP in vertebrate and invertebrate systems. This focus does not exclude the possibility of TGIP in other systems, e.g. plants (for example see Luna and Ton 2012; Henry et al. 2013). Within vertebrates and invertebrates, we address the potential mechanisms by which the phenotypic plasticity can be achieved across generational boundaries. We discuss the ecological conditions where TGIP is expected to evolve, and finish by considering future directions in TGIP research to address outstanding gaps in our knowledge of this fundamental and widespread phenomenon.

Based on its use in the field of ecological and evolutionary immunology, we use a broad definition of TGIP that constitutes any transfer of parental immunological experience to offspring, which can also include examples where the parental immunological experience takes place when developing offspring cells are already present. Under a strict mechanistic definition, this could include both inter- and transgenerational epigenetic inheritance (Heard and Martienssen 2014), but can fit with a broad definition of transgenerational epigenetics (Burggren 2016), where, in this case, a modified immunological phenotype is inherited due to the experiences of parents, without changes in gene sequences. This broad classification of TGIP also includes different phenomena with distinct mechanistic underpinnings. Two broad categories can be characterized: (1) the provisioning of active immune components to offspring, for example maternal antibody transfer in mammals or deposition of antimicrobial peptides in insect eggs, and (2) heightened endogenous immune function of offspring, for example through altered offspring gene expression. The merit of viewing mechanistically distinct phenomena under the same umbrella definition is that we can generally assess the causes and consequences of parental derived modifications to offspring immunological phenotypes. We also note that it is important to compare and contrast these differentiated phenomena when assessing TGIP from an adaptive evolution standpoint.

\section{Evidence for TGIP in vertebrates}

Studies of transgenerational immunity have a long history in vertebrate systems, but what constitutes vertebrate TGIP remains a developing field. Recent studies have demonstrated novel instances of TGIP that relate to both innate and adaptive immune components. Innate immunity is evolutionary conserved and is present in both invertebrates and vertebrates. Due to its immediate activation, it constitutes a rapid reaction against infection. Although recent studies have shown the innate immune system is capable of specificity and can provide lasting protection (Chambers and Schneider 2012; Netea et al. 2016), in general it is considered to be comparatively unspecific. In vertebrates, it acts as the first line of defense, with the highly targeted and specific vertebrate adaptive immune response developing later.

Paul Ehrlich first described the passive transfer of components of the maternal adaptive immune response in 1892, with antibodies being transferred from mothers to offspring via the placenta, milk or eggs (Brambell 1958, 1969; Silverstein 2001). This can boost offspring survival against pathogens isolated from the maternal environment. As the antibody-mediated adaptive immune system of vertebrates requires time to mature (Grindstaff et al. 2006; Boulinier and Staszewski 2008; Hasselquist and Nilsson 2009), TGIP is considered beneficial for early life stages when mortality selection is highest (Rossiter 1996). Selection from parasites is considered to have resulted in the independent evolution of TGIP across vertebrates (Patterson et al. 1962; Hasselquist and Nilsson 2009; Swain and Nayak 2009; de Oya et al. 2011).

In a common aquaculture application, TGIP of teleost fish is taken advantage of to improve offspring survival by boosting parental immunity (Mulero et al. 2007). Effects of TGIP are seen on both innate and adaptive immune responses of fish (Bly et al. 1986; Fuda et al. 1992; Takemura and Takano 1997). Teleost fish mothers deposit antibodies directly into eggs, with primed offspring having increased body weight, lysozyme activity, complement system efficiency, and anti-protease activity (Hanif et al. 2004). Fish are interesting vertebrate model systems to investigate TGIP in an evolutionary ecology framework, as large-scale breeding can permit laboratory manipulation experiments, and novel routes to achieve TGIP may be facilitated by differential parental investment strategies in teleosts (Clutton-Brock 1991; Wourms and Lombardi 1992; Blackburn 2015). For example, in mouthbrooding cichlids active immune substances can be transferred via the oral mucosa to boost offspring immune defense (Sin et al. 1994; Keller et al. 2017). Similarly, in species with paternal care, fathers can provide eggs or fry with antimicrobial immune components in a thick mucus layer, facilitating biparental protection of their offspring (Giacomello et al. 2006; Buckley et al. 2010; Pizzolon et al. 2010). Biparental TGIP influences offspring lymphocyte proliferation and immune gene expression in syngnathids (i.e. seahorses and pipefishes), with their unique male pregnancy (Roth et al. 2012; Beemelmanns and Roth 2016a, b, 2017). In vertebrates, these are currently the only examples for a paternal involvement in TGIP, including the potential involvement of epigenetic mechanisms leading to changes in endogenous offspring immunity, in addition to the transfer of active immune components.

Studies in amphibians and reptiles are limited, but there is some evidence of TGIP in these taxonomic groups. The transfer of maternal antigen-specific antibodies to eggs has 
been shown in African clawed frogs (Xenopus laevis), potentially protecting eggs prior to the development of the offspring immune system (Poorten and Kuhn 2009). Active innate immune components have also been shown to be transferred to embryos from adult glass frogs, Hyalinobatrachium colymbiphyllum (Walke et al. 2011). A study of desert tortoises (Gopherus agassizri) suggested higher Immunoglobulin (Ig) $\mathrm{G}$ and IgM antibody concentrations in offspring from infected parents (Schunlacher et al. 1999). These examples show transfer of active innate and adaptive immune components, but studies are yet to investigate epigenetic changes leading to altered immune responses of the offspring themselves.

In birds, the antibody quantity transferred to offspring via maternal deposition into the eggs corresponds to the maternal antibody titer in the blood during the pre-laying period (Gasparini et al. 2002). Most studies of TGIP in birds have induced parental immunity via the injection of sheep red blood cells or other benign antigens. Specific TGIP has only rarely been experimentally investigated in natural hostparasite systems, e.g. Lyme disease Borrelia burgdorferi (Gasparini et al. 2002) and Newcastle disease virus (Rehmani and Firdous 1995). TGIP in birds enhances offspring defense by elevating offspring immune responsiveness, and maternally transferred antibodies may persist for several weeks up to years after hatching (Ramos et al. 2014). In addition to eggs as a route of maternal antibody transmission, transfer by crop milk feeding has been shown in the pigeon Columba livia (Jacquin et al. 2012). Hence, maternal antibody provisioning via milk feeding (breast or crop) seems to have independently evolved in mammals and birds.

In mammals, maternal vaccination or disease exposure can enhance offspring survival. Most studies, however, have focused on the impact of TGIP on early life stages (Watanaveeradej et al. 2003; Leuridan and Van Damme 2007; Leuridan et al. 2011), while the question of persistent effects of TGIP was largely ignored. Only more recently, it has been demonstrated that maternal vaccination of mice (Mus musculus) with mousepox (VACV WR) increased not only survival of offspring upon a usually lethal infection early in life, but also that this positive impact of TGIP persisted beyond the maturation of the offspring adaptive immune system and into adulthood (Navarini et al. 2010). Studies of wild populations suggest a similar effect, e.g. in a wild sheep population (Ovis aries), maternal antibody concentration was positively correlated with lamb survival (Graham et al. 2010).

Examples from amphibians, reptiles, and mammals have demonstrated the transfer of active innate and adaptive immune components, but studies are yet to explicitly investigate and show evidence for epigenetic changes leading to altered immune responses of the offspring themselves in any of these taxonomic groups. However, given studies in fish showing changes to offspring and even grand-offspring immune gene expression (Beemelmanns and Roth 2017), there is a precedent for TGIP to also be achieved in vertebrates through this route.

\section{Evidence for TGIP in invertebrates}

Despite lacking the characteristic antibody-mediated immune memory achieved by the adaptive immune system in vertebrates, invertebrates have been shown to exhibit functionally analogous responses to immune memory, which provides increased protection on secondary pathogen/parasite exposures. The breadth of taxa with some form of this immune memory-like response is impressive, from comb jellies (Bolte et al. 2013), sea anemones (Brown and Rodriguez-Lanetty 2015) and bivalves, through a variety of crustaceans (Rowley and Pope 2012) and insects (Sadd and Schmid-Hempel 2006; Roth et al. 2009), spanning $>900$ million years of divergence. For within generational immune priming in diverse invertebrates we refer readers to a recent and thorough review of the topic (Milutinović and Kurtz 2016). While evidence for TGIP is less abundant than within generational priming, it has been described for a number of these taxa (Sadd et al. 2005; Watson et al. 2005; Freitak et al. 2009, 2014; Roth et al. 2010).

While much earlier work hinted at TGIP in invertebrates, with increased survival of greater wax moth Galleria mellanoella against bacteria following exposures three generations prior (Ishimori and Metalnikov 1924), there has been a more recent revival of studies into invertebrate TGIP. This began with work in the waterflea Daphnia magna, where it was found that when mothers were exposed to particular strain of the bacterial pathogen Pasteuria ramosa, clonal offspring were better protected to that strain over a heterologous strain (Little et al. 2003). Subsequently, work in the bumblebee Bombus terrestris and the mealworm beetle Tenebrio molitor found priming of antibacterial responses in offspring of mothers exposed to immune eliciting bacterial components (Sadd et al. 2005; Moret 2006). This general pattern of elevated immunity or qualitatively better survival against pathogens in offspring following maternal pathogen exposure has been described in a range of host taxa (various insects, crustaceans, nematodes).

Demonstrations of increased offspring survival to pathogens following prior parental exposure do not require the involvement of immunity. However, other studies have directly measured immune parameters in offspring. Recent gene expression studies have shown that even within insects the routes to the realization of TGIP may be highly diverse. TGIP may elevate baseline expression of immune effectors 
in offspring (Barribeau et al. 2016), prime offspring to induce immune-related genes when required (Trauer-Kizilelma and Hilker 2015), or have diverse effects beyond our understanding of classical innate immunity and resistance (Tate et al. 2017). In addition, depending on the system, only specific types of pathogens may trigger TGIP. For example, in mealworm beetles priming against grampositive bacteria was shown to be more efficient than against gram-negative bacteria (Dhinaut et al. 2018), although in the moth Manduca sexta, TGIP was shown upon inoculation with gram-negative Serratia marcescens (Rosengaus et al. 2017). Concerning the afforded protection, highly specific protection on a strain level (Roth et al. 2010) and cross-reactivity (Dhinaut et al. 2018) have both been shown in related flour beetle systems, indicating that the specificity of protection given by TGIP may also vary greatly among pathogen types and hosts. The work on flour beetles is especially noteworthy, because it has been shown that both mothers and fathers can confer resistance to offspring following immune challenges (Roth et al. 2010; Zanchi et al. 2011). Of relevance for potential mechanisms behind TGIP, an elegant comparison of contemporary step and genetic offspring of the same mother but different fathers showed TGIP only in genetic offspring (Eggert et al. 2014). Other invertebrate systems have been used to demonstrate the persistence of TGIP, which has been shown to cross multiple generational boundaries. Priming of antiviral immunity in the nematode Caenorhabditis elegans can last to F4 progeny (Rechavi et al. 2011). There is suggestive evidence for elevated resistance over multiple generations in the aquatic invertebrate Artemia franciscana following exposure to the pathogen Vibrio campbellii (Norouzitallab et al. 2015, 2016), although this is based on an experimental design with unaccounted for pseudoreplicated.

In invertebrates, both mechanistically distinct routes of achieving TGIP, transfer of active components or induced changes in endogenous offspring immunity, have been demonstrated, including in the same species. For example, in bumblebees, eggs from immune challenged mothers have greater antibacterial activity (Sadd and Schmid-Hempel 2007), but in addition, adult offspring show increased immune gene expression (Barribeau et al. 2016). Also, the studies that demonstrate TGIP across multiple generations in invertebrates are really indicative of underlying epigenetic mechanisms regulating offspring gene expression and phenotypes.

\section{Established and potential mechanisms of TGIP: the unique and the shared}

Comparing the mechanistic underpinnings of TGIP between and within vertebrates and invertebrates provides a great deal of information on convergent evolutionary strategies to adaptively adjust offspring immunity based on the prevailing pathogen environment. Particularly promising is a comparative approach that investigates TGIP contingent on innate immunity, which is relatively conserved between vertebrates and invertebrates. Yet, aside from a few specific cases, e.g. maternal antibody transfer in vertebrates, mechanisms underlying TGIP are relatively poorly understood, and filling this void will require considerable further research effort. However, based on existing knowledge of other plastic physiological traits and immunity, we can suggest potential pathways leading to the realization of TGIP.

\section{Transfer of active immune components}

For decades, the mechanistic basis of TGIP in vertebrates focused on the acquired immune system, and, specifically the transfer of maternal Ig. The transfer of maternal antibodies to offspring has been well documented and reviewed substantially elsewhere (Hasselquist and Nilsson 2009; Swain and Nayak 2009). Data further suggest that the degree of transfer and persistence varies among species and individuals (Boulinier and Staszewski 2008; Garnier et al. 2013). More recent evidence from vertebrates has demonstrated that components of the innate immune system could also be transferred to offspring (Hanif et al. 2004; Beemelmanns and Roth 2016b, 2017).

In teleost fish, the formation of lymphoid tissue, B cells, and $\mathrm{T}$ cells takes time, and thus there is a lag before offspring adaptive immunity becomes effective (Magnadóttir et al. 2005; Swain and Nayak 2009). To overcome this period of high vulnerability, females provide their eggs with adaptive and innate immune components such as complement factors, serine protease-like molecules, lectins, macroglobulin, and antimicrobial peptides (Magnadóttir 2006; Magnadóttir et al. 2005; Swain et al. 2006; Zhang et al. 2013). While fish rely on a combination of both innate and adaptive immune effectors for the transfer of immunity to their offspring, it remains unknown whether similar modes of transfer are at work in other vertebrate clades.

Elevated antibacterial activity has been demonstrated in eggs from immune challenged mothers in insects (Sadd and Schmid-Hempel 2007; Dubuffet et al. 2015). In the snail Biomphalaria glabrata, parental immune protection of eggs takes place through the loading of eggs with an antimicrobial protein (Baron et al. 2013). However, immune activity of eggs may not solely derive from passive transfer, and early stage invertebrate eggs may be capable of producing robust immune responses (Gorman et al. 2004), which result from endogenous immune gene expression (Jacobs et al. 2017). 


\section{Transfer of PAMPs to offspring}

Aside from the direct transfer of immune components between parents and offspring, it is possible that transfer of pathogen associated molecular patterns (PAMPs) to offspring will ready their own endogenous immune responses for the prevailing environment of potential infections. Early transfer of microbes between generations may be much more pronounced than previously thought in animals (Funkhouser and Bordenstein 2013). In insects, mothers exposed to bacterial immune challenge can transfer bacterial fragments to their eggs (Freitak et al. 2014). In honey bees this may be achieved by the nutrition protein vitellogenin acting in a novel role as a potential carrier of an immune priming signal to offspring by binding to PAMPs and transporting bacteria fragments into eggs (Salmela et al. 2015). However, it remains to be investigated if this transfer alone is sufficient to elicit the substantial TGIP responses seen in several insects, and no transfer of bacterial fragments was shown to be associated with TGIP against bacteria in M. sexta moths (Rosengaus et al. 2017).

\section{Epigenetic inheritance influencing offspring gene expression}

Environmental influences can induce epigenetic changes in an organism leading to an altered phenotype that might be maintained across generations (Clutton-Brock 1991; Campos et al. 2014; Jablonka and Lamb 2015; Ragunathan et al. 2015; Rassoulzadegan and Cuzin 2015; Szyf 2015). The contemporary term epigenetics or epigenetic inheritance refers to all nongenetic heritable changes apart from DNAbased changes (mutations) that may lead to altered gene expression and could create phenotypic differences among individuals (Berger et al. 2009; Jablonka and Lamb 2015). Recent studies focusing on the impact of environmental stressors on both vertebrates and invertebrates have confirmed that maternal and paternal experience induces epigenetic changes, such as DNA methylation and histone modifications, which might be transferred over the generational boundary (Heijmans et al. 2008; Szyf 2015; Youngson and Whitelaw 2008; Curley et al. 2011). In humans and mice, epigenetic modifications may play a role in maintaining pools of memory CD8 $\mathrm{T}$ cells following viral infection (Youngblood et al. 2015). In pipefish, parental and grandparental immune challenge leads to the differential expression of 15 genes responsible for epigenetic regulation (DNA methylation and histone de/methylation and de/ acetylation) in subsequent generations (Beemelmanns and Roth 2016b, 2017). Epigenetic modification could thus represent a mechanism for TGIP and the transfer of parental and grandparental immunological experience, with the potential of mediating long-term protection.

\section{DNA methylation}

DNA methylation adds a methyl group $\left(\mathrm{CH}_{3}\right)$ to the $5^{\prime}$ carbon of cytosine bases and generally occurs where a cytosine meets a guanine, at $\mathrm{CpG}$ sites (Bird 2002; Jaenisch and Bird 2003). These sites tend to accumulate in promoter regions forming "CpG islands" (Craig and Bickmore 1994). Hypermethylation of $\mathrm{CpG}$ islands located within or adjacent to promotor regions initiates packing of chromatin structure or heterochromatin remodeling, resulting in gene silencing (Grewal and Moazed 2003). DNA methylation negatively regulates gene expression and is necessary for all cell differentiation processes, such as stem cell differentiation during embryogenesis (Monk et al. 1987; Razin and Shemer 1995; Lee et al. 2015). The chemical reaction of DNA methylation is mediated by enzymatic action of several evolutionarily conserved DNA methyltransferases (DNMTs) involved in either maintaining methylation marks or de novo methylation on previously unmethylated sequences (Okano et al. 1999; Bestor 2000). De novo methylation can thus play an essential role in maternal and paternal imprinting (Kaneda et al. 2004), and is potentially a crucial factor for epigenetic changes based on environmental stress. In contrast to mutations, DNA methylation patterns are reversible, highly dynamic, and can change several times throughout the life of an organism (Monk et al. 1987; Bird 2002; Lee et al. 2015). Recent studies have shown that methylation marks are transferred during meiosis, and are thus heritable across generations (Szyf 2015). It was initially thought that transgenerational epigenetic inheritance through DNA methylation marks was impossible due to embryonic demethylation (Reik et al. 2001); however, other evidence suggests that certain elements escape demethylation, and may represent inherited epimutations (Lane et al. 2003). While derived from a pseudoreplicated experimental design, stochastic methylation patterns have been found across generations of Artemia primed against Vibrio campbellii (Norouzitallab et al. 2016). In addition, DNA methylation genes are differentially expressed in offspring and grand-offspring of immune challenged pipefish individuals exhibiting TGIP (Beemelmanns and Roth 2016a, b, 2017; Roth and Landis 2017). These findings could in principle be suggestive evidence for a role for DNA methylation in TGIP. While methylation is an attractive mechanism for TGIP, recent work on Tenebrio molitor beetles found no evidence of changes in either DNA or RNA methylation during TGIP, but did detect lower proportion of RNA methylation under within generational immune priming (Castro-Vargas et al. 2017). However, this work only quantified global patterns of methylation, leaving open the possibility of altered specific methylation profiles leading to TGIP phenotypes in this system. 


\section{Histone modifications}

Chromatin in its condensed form consists of linked nucleosomes, while the DNA is wrapped tightly around an octamer of core histones (Berger 2002). Accessibility of the DNA for transcription is regulated by addition (acetylation) or removal (deacetylation) of acetyl groups to histone tails, which changes the charge of the histones and the affinity to negatively charged DNA (Wade et al. 1997; Zhang and Reinberg 2001; Berger 2002). Chromatin structure is loose with acetylated histones, and thus is more accessible for transcription, while DNA is bound more tightly by deacetylated histones and transcription is silenced (Perry and Chalkley 1982; Berger 2002). Histone acetyltransferase (HAT) and histone deacetylase enzymes (HDAC) acetylate and deacetylate, respectively (Holbert and Marmorstein 2005), with the balance between their activity significantly impacting gene regulation throughout development and influencing human diseases (Mukherjee et al. 2015). Additionally, histone N-terminal tails are modified by methylation, phosphorylation, and ubiquitination, which are all necessary to accomplish specific functions during the transcription (Zhang and Reinberg 2001; Berger 2002; Holbert and Marmorstein 2005). Histone methylation is catalyzed specifically by histone methyltransferases (HKMT) (Peters and Schübeler 2005) or removed by histone demethylases (Kooistra and Helin 2012). Chromatin modifying processes have been shown to be essential regulators of the activity of many inflammatory genes (Foster and Medzhitov 2009), and studies suggest methylation and acetylation patterns are heritable and that histones pass on epigenetic signals across generations (Campos et al. 2014; Gaydos et al. 2014; Jones 2014). Thus, there is potential for a role of histone modification in TGIP.

TGIP in pipefish is potentially mediated via histone modifications, with offspring and grand-offspring of bacterially immune challenged males exhibiting differential gene expression patterns of genes involved in histone methylation, demethylation, acetylation, and deacetylation (Beemelmanns and Roth 2017). Consistent patterns of paternal and grand-paternal influences on histone modification genes suggest regulation of patrilineal TGIP might be mediated by heritable histone modifications (Beemelmanns and Roth 2017). However, it remains unclear at which exact sites histone modifications might be stably maintained in the gametes of vertebrates, and which mechanisms are responsible for heritable changes mediated by histones.

\section{Small RNAs}

Small RNAs are molecules that are often involved in the regulation of the activity of specific mRNA targets, which may affect a diversity of physiological processes (Kim et al. 2009). As such, small RNAs have been indicated to be involved in controlling immunological reactions (Xiao and Rajewsky 2009; O'Connell et al. 2010; Lawless et al. 2014). Recent data suggested the transfer of one type of maternal small RNA, microRNAs (miRNAs), via breast milk in humans could boost offspring immune responses (Kosaka et al. 2010; Munch et al. 2013). In invertebrates, another small RNA type, small interfering RNAs (siRNAs) have been linked to TGIP. In $C$. elegans, priming of the antiviral response through siRNAs protects against viruses across multiple generations (Rechavi et al. 2011; Sterken et al. 2014; Gammon et al. 2017), although protective siRNA inheritance has not been confirmed in all cases (Ashe et al. 2015). The importance of small RNAs in TGIP more widely, including the breadth of taxa that employ this mechanism, is currently unclear. However, the involvement of small RNAs, which can be transmitted stably through meiosis, in other epigenetic phenomena (Richards 2006) makes them a promising candidate for future studies of the mechanistic underpinnings of TGIP.

\section{TGIP will not always be the rule: adaptive hypotheses and predicted ecological conditions for TGIP}

Vertebrates and invertebrates have multiple pathways by which offspring immunity may be primed based on parental experience of pathogen and parasite exposures. There are two potential adaptive evolutionary hypotheses for the two distinct mechanistic types of TGIP (parental transfer or heightened endogenous offspring immunity) that have been discussed above. Transfer to offspring of active immune components may be beneficial in providing protection to offspring during an otherwise vulnerable period, when the offspring is not yet able to mount its own effective responses. Mechanisms leading to heightened endogenous responses by offspring that are based on parental immune experience will be selected for as they ready offspring for the prevailing parasite and pathogen environment. These hypotheses are not mutually exclusive. For example, transfer of antibodies in vertebrates will protect offspring before they can produce their own antibodies, but in addition, the diversity and quantity of antibodies can mirror the antecedent experienced parasite and pathogen environment of the mother (Grindstaff et al. 2003). It should be noted, however, that a correlation between the levels of an active immune component in mothers and the quantity transferred to offspring does not require an adaptive explanation. A parsimonious explanation could be that this is a simple passive mechanistic consequence of an increased titer of the component in the mother, which requires no link to its effect 
on offspring fitness. The subsequent discussion of the evolution of TGIP assumes the hypothesis that TGIP will ready offspring for the infection risk of the current environment.

While the literature abounds with evidence of TGIP in vertebrate and invertebrate systems, its existence is not universal. For example in invertebrates, several studies have not found evidence for TGIP (Voordouw et al. 2008; Vorburger et al. 2008; Linder and Promislow 2009; Pigeault et al. 2015), and in some cases even reversed patterns of negative effects of parental immune stimulation on offspring resistance have been shown (Vantaux et al. 2014; Littlefair et al. 2017). Such cases may also be more common than the literature suggests as a consequence of publication bias against negative results (Møller and Jennions 2001). The absence of TGIP in these systems may be due to mechanistic constraints preventing TGIP, or that specific assays may miss the relevant immune parameter. For example, the observation of a TGIP phenotype can depend on the physiological immune pathway assayed (Sadd et al. 2005; Trauer-Kizilelma and Hilker 2015). However, the presence or absence of TGIP may have deeper routes pertaining to the evolutionary history of an organism, with the evolution and maintenance of TGIP being dependent on the predictability of parasite and pathogen environments across generations and the fitness-related costs of TGIP to both parents and offspring. In the following section, we discuss these aspects that may influence the evolution of TGIP. Exceptions might exist to these broad generalizations of the underlying ecological determinants relating to the selective advantage of TGIP, and we highlight these where appropriate.

The evolution of TGIP, the degree of specificity or crossreactivity it shows across parasite and pathogen types, and extent of protection it confers to offspring will fundamentally depend on the ecology of the organism in question and the parasites and pathogens that it encounters (Fig. 1). The risks of parasite and pathogen infection are often spatially patchy. When environmental barriers limit parasite dispersal and assemblages of parasite genotypes are stable over generations, it is highly probable that hosts and their offspring will encounter the same parasite genotypes repeatedly (Little and Kraaijeveld 2004). In this case, long-lasting and specific TGIP will be beneficial by facilitating a faster reaction towards the current parasite or pathogen assemblage that is based on the immunological experience of parents (Lui 2000). Hence, ecological conditions where pathogenic communities are stable may select for persistent and multigenerational TGIP (Lemke et al. 1994; Norouzitallab et al. 2015; Beemelmanns and Roth 2017). Likewise, when host dispersal is low the likelihood of similar parasite pressures being encountered across generations increases. Such scenarios will promote the

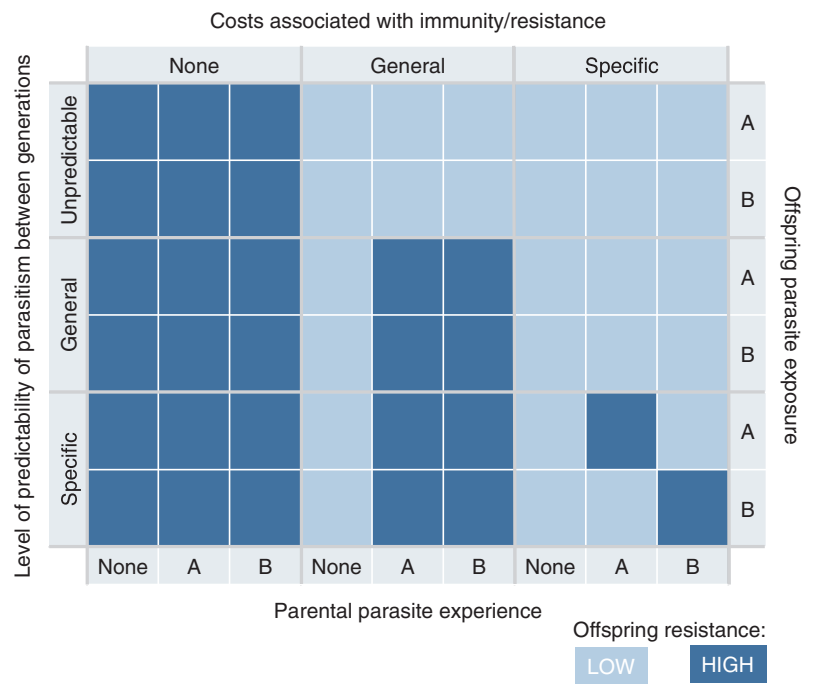

Fig. 1 A simple schematic representing the base expectations of the existence of TGIP when accounting for the predictability of the parasite environment between generations and the costs associated with elevated immunity. In the absence of associated costs, all offspring will be expected to display increased resistance, irrespective of parental experience with parasites and the predictability of the environment across generations. When costs for increased resistance are present, increased resistance is only predicted when the parental environment predicts the parasite environment of offspring, and when parents are exposed to infection (TGIP). Under a framework of specific costs of resistance, parasite-specific TGIP is only expected to evolve when the predictability of the environment across generations is also specific to the parasite types

evolution of TGIP (Pigeault et al. 2016). For similar reasons, models predict that when investment into TGIP is a plastic trait, in species with philopatric and dispersing individuals TGIP will be found only in philopatric individuals (Pigeault et al. 2016). While TGIP is intuitively expected to be present when offspring are more likely to encounter the same parasites and pathogens as their parents, there are exceptions. For instance, TGIP has been described in marine invertebrates like scallops that are broadcast spawners (Yue et al. 2013), where parental experience is unlikely to predict offspring pathogen environment. However, in these cases there is at least a conceivable benefit if TGIP protects against vertically transmitted pathogens, and thus offspring will, by the nature of this transmission route, be exposed to the same pathogens as their parents.

The assumption is that the benefits of increased protection afforded by TGIP will be weighed against costs. If parasite and pathogen pressures fluctuate over generations, TGIP may come at a net cost (von Schantz et al. 1999). Parental effects are shaped by selection on both parents and offspring (Kirkpatrick and Lande 1989; Mousseau and Fox 1998). These levels of selection may frequently oppose each other (Kirkpatrick and Lande 1989; Wolf and Brodie 1998), resulting in costs that can either be inflicted upon the parents, the offspring, or both (Gallizzi et al. 2008). The 
offspring may suffer as TGIP stimulates the young to mount a costly immune response (Carlier and Truyens 1995). Mounting an immune response carries energetic costs, necessitating that resources are allocated away from development, maturation, reproduction, and growth (Sheldon and Verhulst 1996; Lochmiller and Deerenberg 2000; Schmid-Hempel 2005; Ardia et al. 2011, 2012). When considering whether TGIP is to be expected, costs of its implementation are important to take into account. By its very nature as an inducible phenotype, it is predicted that TGIP will carry costs. If this were not the case, the expectation would be for offspring immunity to be maintained at primed levels constantly. Experiments that manipulate the environment encountered by primed offspring have elucidated some of the underlying costs of TGIP. For instance, in bumblebees where a mismatch between maternal immunological experience (bacterial based immune challenge) and offspring parasite environment (trypanosome parasite) was created, costs were seen in that offspring primed to bacteria were more susceptible to the distinct trypanosome parasite than naive offspring (Sadd and Schmid-Hempel 2009). Further costs relating to offspring life-history traits have been highlighted in cases of TGIP in beetles (Roth et al. 2010; Zanchi et al. 2011). In mosquitoes, TGIP has been shown to be negatively correlated with offspring reproduction in the absence of infection (Contreras-Garduño et al. 2014). In vertebrates transfer of antibodies to offspring can hinder the development of an offspring's own immune response (Siegrist 2003), as in the case of antibodies against Newcastle Disease virus in birds (Staszewski and Siitari 2010). In mammals, the transfer of immunity via the placenta can result in a costly inflammation by inducing the complement system and phagocytes (Hanson 2004). There can also be costs associated with TGIP as sexual hormones are depleted, decreasing nestling development and secondary sexual ornaments (Eising et al. 2001; Gil et al. 2006). Theoretical studies predict that TGIP, especially when costly to reproduction, might increase parasite prevalence and destabilize population dynamics in the long term (Tidbury et al. 2012). Thus, further experimental and theoretical work is required to understand the complex interplay between costs and benefits of TGIP.

Given the balance of costs and benefits based on the predictability of the parasite and pathogen environment, only under certain conditions will TGIP be favored and have an adaptive benefit (Fig. 1). If these conditions of environment, costs and benefits, and relationship between parents and offspring are not met, then we expect that TGIP will be absent or non-specific. If an environment is heterogenous with regard to the probability of infection, but parasite and pathogen types are not stable over time, then it could be expected that priming of a general immune response will be favored (Fig. 1). Furthermore, the existence of TGIP could be mechanistically constrained, and thus particular immune pathways may not show immune priming or certain pathogens and parasites may not elicit it. The wider community of parasites and pathogens may even dictate constraints on the expression of TGIP phenotypes, as demonstrated in flour beetles where parental co-infection with a gut protozoan curtailed the normally observed TGIP against bacteria (Tate and Graham 2015).

While many prerequisites need to be fulfilled for TGIP to evolve, spread and be maintained, it only requires one factor to be absent or the relative costs of TGIP to be too high for its evolution to be obstructed. In some examples of studies failing to demonstrate TGIP there are logical grounds for its absence. For example, in mosquitoes (Aedes aegypti) no effects in offspring following the stimulation of the maternal melanization response were detected (Voordouw et al. 2008). However, eggs of A. aegypti are usually laid in ephemeral pools of water that are unlikely to be shared across generations. Thus, the parasite environment experienced by a mother may not be tightly correlated with the offspring environment, and as such, it is perhaps unsurprising that costly TGIP is predominantly absent. Interestingly, recent work in invertebrates has demonstrated that offspring may be primed to differing stages of the immune response, with recognition, signaling, or effectors being more readily induced, or that offspring exhibit heightened levels of constitutive immune expression (Trauer-Kizilelma and Hilker 2015; Barribeau et al. 2016; Tate et al. 2017). It is plausible that these various levels of priming, from a readied state to elevated production of effector molecules are a consequence of the predictability of the parasite environment between generations. In systems where the likelihood of offspring encountering the same parasite and pathogen pressures as parents is high, it may pay for offspring to invest fully into heightened constitutive immunity, whereas in cases where the likelihood is lower, just being ready, with sensitized recognition or signaling, may be beneficial.

Sex role reversed vertebrate species may further inform of the ecological conditions that can support TGIP evolution. TGIP was traditionally thought to be exclusively maternal in vertebrates, mediated by the maternal antibody transfer (Gasparini et al. 2002; Reid et al. 2006; Swain and Nayak 2009), being supported by findings showing unchanged antibody titers in vertebrates when fathers, but not mothers, were immune challenged (Gasparini et al. 2002; Reid et al. 2006). Males may be considered unable to transfer immunity because sperm are simply too small to transfer much more than just DNA (Wassarman et al. 2001; Arnqvist and Rowe 2005), but there is also an evolutionary benefit argument that offspring are more likely to encounter a similar parasite and pathogen environment to their mothers than their fathers. However, these limitations may 
not hold in animals with extreme paternal care. For instance, the sex-role reversed pipefish Syngnathus typhle has biparental TGIP (Roth et al. 2012; Beemelmanns and Roth 2016a, b, 2017; Roth and Landis 2017). In S. typhle, males have evolved a unique placenta-like structure in the male brood pouch for nutrient and oxygen transfer (Wilson et al. 2001; Dzyuba et al. 2006; Harlin-Cognato et al. 2006; Stölting and Wilson 2007; Ripley and Foran 2009), but it may also facilitate TGIP. In Syngnathids with their male pregnancy, selection for biparental immune priming is likely due to the intimate connection of the father with the offspring both from an ultimate and a proximate view. Offspring are born in the environment of the father, and are hence exposed to the paternal parasite pressure (Roth et al. 2012)

From an evolutionary perspective, it is clear that the existence of TGIP will not be the ubiquitous default, and will depend on the presence of a suite of factors favoring its evolution and maintenance. Examples contradicting the predictions of the benefits of TGIP will be enormously informative to understanding the generality of this system of defense, but may be underrepresented in the published literature.

\section{Future outlook}

Although the term transgenerational immunity was originally coined for the transfer of maternal antibodies to offspring in vertebrates, it has become apparent that the concept has considerably broader consequences, taxonomically, immunologically, and in terms of mechanisms underlying trans-generationally primed phenotypes. Simplistically speaking, however, the existence of similar functional outcomes across vertebrate and invertebrate groups suggests common selective pressures from parasites and pathogens leading to the priming of offspring immunity dependent on parental experience. Yet, there remains a great deal that is unknown about the mechanistic causes and ecological and evolutionary consequences of TGIP.

To substantially add to our understanding of TGIP, studies need to step away from only measuring classical routes and immune parameters. For example, it is now apparent that TGIP in vertebrates is much more than maternal antibody transfer, and endogenous immune-related gene expression of offspring can be significantly altered (Roth et al. 2012; Beemelmanns and Roth 2016a, b, 2017; Roth and Landis 2017). Rapid advancements in sequencing technologies now allow for the TGIP phenotype to be tied to genome-wide transcriptomic patterns, and this has been informative in invertebrate systems (Trauer-Kizilelma and Hilker 2015; Barribeau et al. 2016; Tate et al. 2017). Where study systems permit, future work should aim to assess temporal changes in gene expression and how these are linked to infection dynamics, as has been performed in the flour beetle-bacteria system (Tate et al. 2017).

More comparative studies should also be undertaken. While it is expected that the particulars of TGIP phenotypes may be host and parasite system specific, such approaches have the potential to reveal broader commonalities. Furthermore, comparative studies are necessary to directly test some of the hypotheses that relate to the existence and extent of TGIP in relation to the ecological setting within which organisms have evolved. Much of the discussion about the ecological conditions surrounding the evolution of TGIP remains speculative. We require extensive comparative studies that compare the existence of TGIP across categories of organisms that are predicted to differ, e.g. with different philopatric tendencies.

Further work is required to uncover the underlying mechanisms of TGIP. While many candidate mechanisms exist, that could be responsible in both vertebrates and invertebrates, stringent tests of these mechanisms have yet to be carried out. Epigenetic markers in offspring or the presence of apparently sampled antigens from the parental environment is, however, not enough. Causal links must be established that associate these potential mechanistic routes and the actual offspring phenotypes. Little knowledge exists about epigenetic mechanisms that could potentially regulate host-pathogen interactions and the development of host immune defense strategies (Gómez-Díaz et al. 2012). Numerous studies indicate that epigenetic mechanisms fulfill a crucial role in regulating the transcription of immune-related genes upon infections (Huang and Wells 2014; Marr et al. 2014; Okamoto et al. 2014; Smale et al. 2014). Pathogen exposure of the parental generation might mediate epigenetic marks that could be passed on as protective cues to the offspring and subsequent generations. How epigenetic effects are involved in TGIP is still unresolved, and empirical data that follow parental and filial phenotypes through time in controlled experiments are needed. Non-DNA-based inheritance as one form of multigenerational plasticity might be more widespread than previously thought, leading to claims for a more wideranging view of inheritance and adaptation (Danchin et al. 2011). To what extent these epigenetic effects are adaptively beneficial and play a role in driving phenotypic variation of traits across generations is so far poorly understood. TGIP, particularly in systems amenable to highthroughput study, offers a conceptual framework within which generalizations about epigenetic effects and their ecological and evolutionary consequences may be interpreted.

Acknowledgements We thank Paul Schmid-Hempel for his guidance in the field of Ecological Immunology with more than a decade of 
inspiring discussions, and for creating an academic environment that fostered the intellectual and personal relationships that produced this manuscript and many others. We also thank the editors of this special issue, Becky Rosengaus, and two anonymous reviewers for constructive comments on the manuscript. OR was supported by Research Grants from the Volkswagen Stiftung, the German Research Foundation (DFG: 237263721; 349393951; 274695381) and a Starting Grant from the European Research Council (MALEPREG). AB was supported by a stipend from the International Max Planck Research School for Evolutionary Biology (IMPRS). SMB was supported by the kindness and naiveté of strangers. BMS was supported by National Science Foundation IOS 16-54028 and an Illinois State University New Faculty Research Initiative Grant.

\section{Compliance with ethical standards}

Conflict of interest The authors declare that they have no conflict of interest.

\section{References}

Agrawal AA, Laforsch C, Tollrian R (1999) Transgenerational induction of defences in animals and plants. Nature 401:60

Ardia DR, Gantz JE, Brent C, Strebel S (2012) Costs of immunity in insects: an induced immune response increases metabolic rate and decreases antimicrobial activity. Funct Ecol 26:732-739

Ardia DR, Parmentier HK, Vogel LA (2011) The role of constraints and limitation in driving individual variation in immune response. Funct Ecol 25:61-73

Arnqvist G, Rowe L (2005) Sexual conflict. Princeton University Press, Princeton, NJ.

Ashe A, Sarkies P, Le Pen J, Tanguy M, Miska EA (2015) Antiviral RNA interference against Orsay virus is neither systemic nor transgenerational in Caenorhabditis elegans. J Virol 89:12035-12046

Baron OL, Van West P, Ponchet M, Dubreuil G, Gourbal B, Reichhart J-M et al. (2013) Parental transfer of the antimicrobial protein LBP/BPI protects Biomphalaria glabrata eggs against oomycete infections. PLoS Pathog 9:e1003792

Barribeau SM, Schmid-Hempel P, Sadd BM (2016) Royal decree: gene expression in trans-generationally immune primed bumblebee workers mimics a primary immune response. PLOS ONE 11:e0159635

Beemelmanns A, Roth O (2016a) Bacteria-type-specific biparental immune priming in the pipefish Syngnathus typhle. Ecol Evol 6:6735-6757

Beemelmanns A, Roth O (2016b) Biparental immune priming in the pipefish Syngnathus typhle. Zoology 119:262-272

Beemelmanns A, Roth O (2017) Grandparental immune priming in the pipefish Syngnathus typhle. BMC Evol Biol 17:44

Berger SL (2002) Histone modifications in transcriptional regulation. Curr Opin Genet Dev 12:142-148

Berger SL, Kouzarides T, Shiekhattar R, Shilatifard A (2009) An operational definition of epigenetics. Genes Dev 23:781-783

Bestor TH (2000) The DNA methyltransferases of mammals. Hum Mol Genet 9:2395-2402

Bird A (2002) DNA methylation patterns and epigenetic memory. Genes Dev 16:6-21

Blackburn DG (2015) Evolution of vertebrate viviparity and specializations for fetal nutrition: a quantitative and qualitative analysis. J Morphol 276:961-990

Bly JE, Grimm A, Morris I (1986) Transfer of passive immunity from mother to young in a teleost fish: haemagglutinating activity in the serum and eggs of plaice, Pleuronectes platessa L. Comp Biochem Physiol A Mol Integr Physiol 84:309-313

Bolte S, Roth O, Philipp EE, Saphörster J, Rosenstiel P, Reusch TB (2013) Specific immune priming in the invasive ctenophore Mnemiopsis leidyi. Biol Lett 9:20130864

Bonduriansky R (2012) Rethinking heredity, again. Trends Ecol Evol 27:330-336

Bonduriansky R, Day T (2009) Nongenetic inheritance and its evolutionary implications. Annu Rev Ecol Evol Syst 40:103-125

Boulinier T, Staszewski V (2008) Maternal transfer of antibodies: raising immuno-ecology issues. Trends Ecol Evol 23:282-288

Brambell FR (1969) The transmission of immune globulins from the mother to the foetal and newborn young. Proc Nutr Soc 28:35-41

Brambell FWR (1958) The passive immunity of the young mammal. Biol Rev 33:488-531

Brown T, Rodriguez-Lanetty M (2015) Defending against pathogens-immunological priming and its molecular basis in a sea anemone, cnidarian. Sci Rep 5:17425

Buckley J, Maunder RJ, Foey A, Pearce J, Val AL, Sloman KA (2010) Biparental mucus feeding: a unique example of parental care in an Amazonian cichlid. J Exp Biol 213:3787-3795

Burggren W (2016) Epigenetic inheritance and its role in evolutionary biology: re-evaluation and new perspectives. Biology 5:24

Campos EI, Stafford JM, Reinberg D (2014) Epigenetic inheritance: histone bookmarks across generations. Trends Cell Biol 24:664-674

Carlier Y, Truyens C (1995) Influence of maternal infection on offspring resistance towards parasites. Parasitol Today 11:94-99

Carone BR, Fauquier L, Habib N, Shea JM, Hart CE, Li R et al. (2010) Paternally induced transgenerational environmental reprogramming of metabolic gene expression in mammals. Cell 143:1084-1096

Castro-Vargas C, Linares-López C, López-Torres A, Wrobel K, Torres-Guzmán JC, Hernández GA et al. (2017) Methylation on RNA: a potential mechanism related to immune priming within but not across generations. Front Microbiol 8:473

Chambers MC, Schneider DS (2012) Pioneering immunology: insect style. Curr Opin Immunol 24:10-14

Clutton-Brock TH (1991) The evolution of parental care. Princeton University Press, Princeton, NJ.

Contreras-Garduño J, Rodríguez M, Rodríguez M, Alvarado-Delgado A, Lanz-Mendoza H (2014) Cost of immune priming within generations: trade-off between infection and reproduction. Microbes Infect 16:261-267

Craig JM, Bickmore WA (1994) The distribution of CpG islands in mammalian chromosomes. Nat Genet 7:376

Crean AJ, Bonduriansky R (2014) What is a paternal effect? Trends Ecol Evol 29:554-559

Crean AJ, Dwyer JM, Marshall DJ (2013) Adaptive paternal effects? Experimental evidence that the paternal environment affects offspring performance. Ecology 94:2575-2582

Curley JP, Mashoodh R, Champagne FA (2011) Epigenetics and the origins of paternal effects. Horm Behav 59:306-314

Danchin É, Charmantier A, Champagne FA, Mesoudi A, Pujol B, Blanchet S (2011) Beyond DNA: integrating inclusive inheritance into an extended theory of evolution. Nat Rev Genet 12:475

de Oya NJ, Alonso-Padilla J, Blázquez A-B, Escribano-Romero E, Escribano JM, Saiz J-C (2011) Maternal transfer of antibodies to the offspring after mice immunization with insect larvae-derived recombinant hepatitis E virus ORF-2 proteins. Virus Res 158:28-32

Dhinaut J, Chogne M, Moret Y (2018) Immune priming specificity within and across generations reveals the range of pathogens affecting evolution of immunity in an insect. J Anim Ecol 87:448-463 
Donelson J, Munday P, McCormick M, Pitcher C (2012) Rapid transgenerational acclimation of a tropical reef fish to climate change. Nat Clim Chang 2:30-32

Dubuffet A, Zanchi C, Boutet G, Moreau J, Teixeira M, Moret Y (2015) Trans-generational immune priming protects the eggs only against Gram-positive bacteria in the mealworm beetle. PLoS Pathog 11:e1005178

Dzyuba B, Van Look KJ, Cliffe A, Koldewey HJ, Holt WV (2006) Effect of parental age and associated size on fecundity, growth and survival in the yellow seahorse Hippocampus kuda. J Exp Biol 209:3055-3061

Eggert H, Kurtz J, Diddens-de Buhr MF (2014) Different effects of paternal trans-generational immune priming on survival and immunity in step and genetic offspring. Proc Biol Sci 281:20142089

Eising CM, Eikenaar C, Schwabl H, Groothuis TG (2001) Maternal androgens in black-headed gull (Larus ridibundus) eggs: consequences for chick development. Proc Biol Sci 268:839-846

Foster SL, Medzhitov R (2009) Gene-specific control of the TLRinduced inflammatory response. Clin Immunol 130:7-15

Freitak D, Heckel DG, Vogel H (2009) Dietary-dependent trans-generational immune priming in an insect herbivore. Proc Biol Sci 276:2617-2624

Freitak D, Schmidtberg H, Dickel F, Lochnit G, Vogel H, Vilcinskas A (2014) The maternal transfer of bacteria can mediate transgenerational immune priming in insects. Virulence 5:547-554

Fuda H, Hara A, Yamazaki F, Kobayashi K (1992) A peculiar immunoglobulin $\mathrm{M}$ (IgM) identified in eggs of chum salmon (Oncorhynchus keta). Dev Comp Immunol 16:415-423

Funkhouser LJ, Bordenstein SR (2013) Mom knows best: the universality of maternal microbial transmission. PLoS Biol 11: e1001631

Gallizzi K, Alloitteau O, Harrang E, Richner H (2008) Fleas, parental care, and transgenerational effects on tick load in the great tit. Behav Ecol 19:1225-1234

Gammon DB, Ishidate T, Li L, Gu W, Silverman N, Mello CC (2017) The antiviral RNA interference response provides resistance to lethal arbovirus infection and vertical transmission in Caenorhabditis elegans. Curr Biol 27:795-806

Garnier R, Boulinier T, Gandon S (2013) Evolution of the temporal persistence of immune protection. Biol Lett 9:20130017

Gasparini J, McCoy KD, Tveraa T, Boulinier T (2002) Related concentrations of specific immunoglobulins against the Lyme disease agent Borrelia burgdorferi sensu lato in eggs, young and adult of the kittiwake (Rissa tridactyla). Ecol Lett 5:519-524

Gaydos LJ, Wang W, Strome S (2014) H3K27me and PRC2 transmit a memory of repression across generations and during development. Science 345:1515-1518

Giacomello E, Marchini D, Rasotto MB (2006) A male sexually dimorphic trait provides antimicrobials to eggs in blenny fish. Biol Lett 2:330-333

Gil D, Marzal A, de Lope F, Puerta M, Møller AP (2006) Female house martins (Delichon urbica) reduce egg androgen deposition in response to a challenge of their immune system. Behav Ecol Sociobiol 60:96-100

Goellner K, Conrath U (2008) Priming: it's all the world to induced disease resistance. Eur J Plant Pathol 121:233-242

Gómez-Díaz E, Jordà M, Peinado MA, Rivero A (2012) Epigenetics of host-pathogen interactions: the road ahead and the road behind. PLoS Pathog 8:e1003007

Gorman M, Kankanala P, Kanost M (2004) Bacterial challenge stimulates innate immune responses in extra-embryonic tissues of tobacco hornworm eggs. Insect Mol Biol 13:19-24

Graham AL, Hayward AD, Watt KA, Pilkington JG, Pemberton JM, Nussey DH (2010) Fitness correlates of heritable variation in antibody responsiveness in a wild mammal. Science 330:662-665
Grewal SI, Moazed D (2003) Heterochromatin and epigenetic control of gene expression. Science 301:798-802

Grindstaff JL, Brodie ED, Ketterson ED (2003) Immune function across generations: integrating mechanism and evolutionary process in maternal antibody transmission. Proc Biol Sci 270:2309-2319

Grindstaff JL, Hasselquist D, Nilsson J-Å, Sandell M, Smith HG, Stjernman M (2006) Transgenerational priming of immunity: maternal exposure to a bacterial antigen enhances offspring humoral immunity. Proc Biol Sci 273:2551-2557

Hanif A, Bakopoulos V, Dimitriadis G (2004) Maternal transfer of humoral specific and non-specific immune parameters to sea bream (Sparus aurata) larvae. Fish Shellfish Immunol 17:411-435

Hanson LA (2004). Immunobiology of human milk: how breastfeeding protects babies. Pharmasoft Pub, Amarillo, TX

Harlin-Cognato A, Hoffman EA, Jones AG (2006) Gene cooption without duplication during the evolution of a male-pregnancy gene in pipefish. Proc Natl Acad Sci USA 103:19407-19412

Hasselquist D, Nilsson J-Å (2009) Maternal transfer of antibodies in vertebrates: trans-generational effects on offspring immunity. Philos Trans R Soc Lond B Biol Sci 364:51-60

Heard E, Martienssen RA (2014) Transgenerational epigenetic inheritance: myths and mechanisms. Cell 157:95-109

Heijmans BT, Tobi EW, Stein AD, Putter H, Blauw GJ, Susser ES et al. (2008) Persistent epigenetic differences associated with prenatal exposure to famine in humans. Proc Natl Acad Sci USA 105:17046-17049

Henry E, Yadeta KA, Coaker G (2013) Recognition of bacterial plant pathogens: local, systemic and transgenerational immunity. New Phytol 199:908-915

Holbert MA, Marmorstein R (2005) Structure and activity of enzymes that remove histone modifications. Curr Opin Struct Biol 15:673-680

Huang E, Wells CA (2014) The ground state of innate immune responsiveness is determined at the interface of genetic, epigenetic, and environmental influences. J Immunol 193:13-19

Ishimori N, Metalnikov S (1924) Immunisation de la chenille de Galleria mellonella par des substances non spécifiques. Compt Rend Acad Sci, Paris 178:2136-2138

Jablonka E, Lamb MJ (2015) The inheritance of acquired epigenetic variations. Int J Epidemiol 44:1094-1103

Jacobs CG, Gallagher JD, Evison SE, Heckel DG, Vilcinskas A, Vogel $\mathrm{H}$ (2017) Endogenous egg immune defenses in the yellow mealworm beetle (Tenebrio molitor). Dev Comp Immunol 70:1-8

Jacquin L, Blottiere L, Haussy C, Perret S, Gasparini J (2012) Prenatal and postnatal parental effects on immunity and growth in 'lactating' pigeons. Funct Ecol 26:866-875

Jaenisch R, Bird A (2003) Epigenetic regulation of gene expression: how the genome integrates intrinsic and environmental signals. Nat Genet 33:245

Jiang L, Zhang J, Wang J-J, Wang L, Zhang L, Li G et al. (2013) Sperm, but not oocyte, DNA methylome is inherited by zebrafish early embryos. Cell 153:773-784

Jones B (2014) Epigenetics: histones pass the message on. Nat Rev Genet 16:3

Kaneda M, Okano M, Hata K, Sado T, Tsujimoto N, Li E et al. (2004) Essential role for de novo DNA methyltransferase Dnmt3a in paternal and maternal imprinting. Nature 429:900

Kaufmann J, Lenz TL, Milinski M, Eizaguirre C (2014) Experimental parasite infection reveals costs and benefits of paternal effects. Ecol Lett 17:1409-1417

Keller IS, Salzburger W, Roth O (2017) Parental investment matters for maternal and offspring immune defense in the mouthbrooding cichlid Astatotilapia burtoni. BMC Evol Biol 17:264 
Kim VN, Han J, Siomi MC (2009) Biogenesis of small RNAs in animals. Nat Rev Mol Cell Biol 10:126

Kirkpatrick M, Lande R (1989) The evolution of maternal characters. Evolution 43:485-503

Kokko H, Jennions MD (2008) Parental investment, sexual selection and sex ratios. J Evol Biol 21:919-948

Kooistra SM, Helin K (2012) Molecular mechanisms and potential functions of histone demethylases. Nat Rev Mol Cell Biol 13: nrm3327

Kosaka N, Izumi H, Sekine K, Ochiya T (2010) microRNA as a new immune-regulatory agent in breast milk. Silence 1:7

Lane N, Dean W, Erhardt S, Hajkova P, Surani A, Walter J et al. (2003) Resistance of IAPs to methylation reprogramming may provide a mechanism for epigenetic inheritance in the mouse. Genesis 35:88-93

Lawless N, Vegh P, O'Farrelly C, Lynn DJ (2014) The role of microRNAs in bovine infection and immunity. Front Immunol $5: 611$

Lee HJ, Lowdon RF, Maricque B, Zhang B, Stevens M, Li D et al. (2015) Developmental enhancers revealed by extensive DNA methylome maps of zebrafish early embryos. Nat Commun 6:6315

Lemke H, Lange H, Berek C (1994) Maternal immunization modulates the primary immune response to 2-phenyl-oxazolone in BALB/c mice. Eur J Immunol 24:3025-3030

Leuridan E, Hens N, Hutse V, Aerts M, Van Damme P (2011) Kinetics of maternal antibodies against rubella and varicella in infants. Vaccine 29:2222-2226

Leuridan E, Van Damme P (2007) Passive transmission and persistence of naturally acquired or vaccine-induced maternal antibodies against measles in newborns. Vaccine 25:6296-6304

Linder JE, Promislow DE (2009) Cross-generational fitness effects of infection in Drosophila melanogaster. Fly 3:143-150

Little TJ, Kraaijeveld AR (2004) Ecological and evolutionary implications of immunological priming in invertebrates. Trends Ecol Evol 19:58-60

Little TJ, O'Connor B, Colegrave N, Watt K, Read AF (2003) Maternal transfer of strain-specific immunity in an invertebrate. Curr Biol 13:489-492

Littlefair JE, Laughton AM, Knell RJ (2017) Maternal pathogen exposure causes diet-and pathogen-specific transgenerational costs. Oikos 126:82-90

Lochmiller RL, Deerenberg C (2000) Trade-offs in evolutionary immunology: just what is the cost of immunity? Oikos 88:87-98

Lui KJ (2000) Confidence intervals of the simple difference between the proportions of a primary infection and a secondary infection, given the primary infection. Biom J 42:59-69

Luna E, Ton J (2012) The epigenetic machinery controlling transgenerational systemic acquired resistance. Plant Signal Behav 7:615-618

Magnadóttir B (2006) Innate immunity of fish (overview). Fish Shellfish Immunol 20:137-151

Magnadóttir B, Lange S, Gudmundsdottir S, Bøgwald J, Dalmo R (2005) Ontogeny of humoral immune parameters in fish. Fish Shellfish Immunol 19:429-439

Marr AK, MacIsaac JL, Jiang R, Airo AM, Kobor MS, McMaster WR (2014) Leishmania donovani infection causes distinct epigenetic DNA methylation changes in host macrophages. PLoS Pathog 10: e1004419

Milutinović B,Kurtz J,(2016) Immune memory in invertebrates Semin Immunol 28:328-342

Mitchell SE, Read AF (2005) Poor maternal environment enhances offspring disease resistance in an invertebrate. Proc Biol Sci 272:2601-2607

Møller AP, Jennions MD (2001) Testing and adjusting for publication bias. Trends Ecol Evol 16:580-586
Monk M, Boubelik M, Lehnert S (1987) Temporal and regional changes in DNA methylation in the embryonic, extraembryonic and germ cell lineages during mouse embryo development. Development 99:371-382

Moreau J, Martinaud G, Troussard JP, Zanchi C, Moret Y (2012) Trans-generational immune priming is constrained by the maternal immune response in an insect. Oikos 121:1828-1832

Moret Y (2006) 'Trans-generational immune priming': specific enhancement of the antimicrobial immune response in the mealworm beetle, Tenebrio molitor. Proc Biol Sci 273:1399-1405

Mousseau TA, Fox CW (1998) The adaptive significance of maternal effects. Trends Ecol Evol 13:403-407

Mukherjee K, Twyman RM, Vilcinskas A (2015) Insects as models to study the epigenetic basis of disease. Prog Biophys Mol Biol 118:69-78

Mulero I, García-Ayala A, Meseguer J, Mulero V (2007) Maternal transfer of immunity and ontogeny of autologous immunocompetence of fish: a minireview. Aquaculture 268: 244-250

Munch EM, Harris RA, Mohammad M, Benham AL, Pejerrey SM, Showalter L et al. (2013) Transcriptome profiling of microRNA by Next-Gen deep sequencing reveals known and novel miRNA species in the lipid fraction of human breast milk. PLOS ONE 8: e50564

Navarini AA, Krzyzowska M, Lang KS, Horvath E, Hengartner H, Niemialtowski MG et al. (2010) Long-lasting immunity by early infection of maternal-antibody-protected infants. Eur J Immunol 40:113-116

Netea MG, Joosten LA, Latz E, Mills KH, Natoli G, Stunnenberg HG et al. (2016) Trained immunity: a program of innate immune memory in health and disease. Science 352:aaf1098

Norouzitallab P, Baruah K, Biswas P, Vanrompay D, Bossier P (2016) Probing the phenomenon of trained immunity in invertebrates during a transgenerational study, using brine shrimp Artemia as a model system. Sci Rep 6:21166

Norouzitallab P, Biswas P, Baruah K, Bossier P (2015) Multigenerational immune priming in an invertebrate parthenogenetic Artemia to a pathogenic Vibrio campbellii. Fish Shellfish Immunol 42:426-429

O'Connell RM, Rao DS, Chaudhuri AA, Baltimore D (2010) Physiological and pathological roles for microRNAs in the immune system. Nat Rev Immunol 10:111

Okamoto Y, Shinjo K, Shimizu Y, Sano T, Yamao K, Gao W et al. (2014) Hepatitis virus infection affects DNA methylation in mice with humanized livers. Gastroenterology 146:562-572

Okano M, Bell DW, Haber DA, Li E (1999) DNA methyltransferases Dnmt3a and Dnmt3b are essential for de novo methylation and mammalian development. Cell 99:247-257

Patterson R, Youngner JS, Weigle WO, Dixon FJ (1962) Antibody production and transfer to egg yolk in chickens. J Immunol 89:272-278

Perry M, Chalkley R (1982) Histone acetylation increases the solubility of chromatin and occurs sequentially over most of the chromatin. A novel model for the biological role of histone acetylation. J Biol Chem 257:7336-7347

Peters AH, Schübeler D (2005) Methylation of histones: playing memory with DNA. Curr Opin Cell Biol 17:230-238

Pigeault R, Garnier R, Rivero A, Gandon S (2016) Evolution of transgenerational immunity in invertebrates. Proc Biol Sci 283:20161136

Pigeault R, Vézilier J, Nicot A, Gandon S, Rivero A (2015) Transgenerational effect of infection in Plasmodium-infected mosquitoes. Biol Lett 11:20141025

Pizzolon M, Giacomello E, Marri L, Marchini D, Pascoli F, Mazzoldi $\mathrm{C}$ et al. (2010) When fathers make the difference: efficacy of male 
sexually selected antimicrobial glands in enhancing fish hatching success. Funct Ecol 24:141-148

Poorten TJ, Kuhn RE (2009) Maternal transfer of antibodies to eggs in Xenopus laevis. Dev Comp Immunol 33:171-175

Ragunathan K, Jih G, Moazed D (2015) Epigenetic inheritance uncoupled from sequence-specific recruitment. Science 348:1258699

Ramos R, Garnier R, González-Solís J, Boulinier T (2014) Long antibody persistence and transgenerational transfer of immunity in a long-lived vertebrate. Am Nat 184:764-776

Rando OJ (2012) Daddy issues: paternal effects on phenotype. Cell 151:702-708

Rassoulzadegan M, Cuzin F (2015) Epigenetic heredity: RNA-mediated modes of phenotypic variation. Ann NY Acad Sci 1341:172-175

Razin A, Shemer R (1995) DNA methylation in early development. Hum Mol Genet 4:1751-1755

Rechavi O, Minevich G, Hobert O (2011) Transgenerational inheritance of an acquired small RNA-based antiviral response in $C$. elegans. Cell 147:1248-1256

Rehmani SF, Firdous S (1995) Passive immunity in chicks from a laying flock vaccinated with the Mukteswar strain of Newcastle disease virus. Prev Vet Med 23:111-118

Reid JM, Arcese P, Keller LF, Hasselquist D (2006) Long-term maternal effect on offspring immune response in song sparrows Melospiza melodia. Biol Lett 2:573-576

Reik W, Dean W, Walter J (2001) Epigenetic reprogramming in mammalian development. Science 293:1089-1093

Richards EJ (2006) Inherited epigenetic variation-revisiting soft inheritance. Nat Rev Genet 7:395

Ripley JL, Foran CM (2009) Direct evidence for embryonic uptake of paternally-derived nutrients in two pipefishes (Syngnathidae: Syngnathus spp.). J Comp Physiol B 179:325-333

Rosengaus RB, Hays N, Biro C, Kemos J, Zaman M, Murray J et al. (2017) Pathogen-induced maternal effects result in enhanced immune responsiveness across generations. Ecol Evol 7:2925-2935

Rossiter M (1996) Incidence and consequences of inherited environmental effects. Annu Rev Ecol Syst 27:451-476

Roth O, Joop G, Eggert H, Hilbert J, Daniel J, Schmid-Hempel P et al. (2010) Paternally derived immune priming for offspring in the red flour beetle, Tribolium castaneum. J Anim Ecol 79:403-413

Roth O, Klein V, Beemelmanns A, Scharsack JP, Reusch TB (2012) Male pregnancy and biparental immune priming. Am Nat 180:802-814

Roth O, Landis SH (2017) Trans-generational plasticity in response to immune challenge is constrained by heat stress. Evol Appl 10:514-528

Roth O, Sadd BM, Schmid-Hempel P, Kurtz J (2009) Strain-specific priming of resistance in the red flour beetle, Tribolium castaneum. Proc Biol Sci 276:145-151

Rowley AF, Pope EC (2012) Vaccines and crustacean aquaculture-a mechanistic exploration. Aquaculture 334:1-11

Sadd BM, Kleinlogel Y, Schmid-Hempel R, Schmid-Hempel P (2005) Trans-generational immune priming in a social insect. Biol Lett $1: 386-388$

Sadd BM, Schmid-Hempel P (2006) Insect immunity shows specificity in protection upon secondary pathogen exposure. Curr Biol 16:1206-1210

Sadd BM, Schmid-Hempel P (2007) Facultative but persistent transgenerational immunity via the mother's eggs in bumblebees. Curr Biol 17:R1046-R1047

Sadd BM, Schmid-Hempel P (2009) PERSPECTIVE: principles of ecological immunology. Evol Appl 2:113-121
Salmela H, Amdam GV, Freitak D (2015) Transfer of immunity from mother to offspring is mediated via egg-yolk protein vitellogenin. PLoS Pathog 11:e1005015

Scheiner SM (2014) The genetics of phenotypic plasticity. XIII. Interactions with developmental instability. Ecol Evol 4:1347-1360

Schmid-Hempel P (2005) Natural insect host-parasite systems show immune priming and specificity: puzzles to be solved. Bioessays 27:1026-1034

Schunlacher I, Rostal DC, Yates RA, Brown DR, Jacobson ER, Klein PA (1999) Persistence of maternal antibodies against Mycoplasma agassizii in desert tortoise hatchlings. Am J Vet Res 60:826-831

Shama LN, Wegner KM (2014) Grandparental effects in marine sticklebacks: transgenerational plasticity across multiple generations. J Evol Biol 27:2297-2307

Sheldon BC, Verhulst S (1996) Ecological immunology: costly parasite defences and trade-offs in evolutionary ecology. Trends Ecol Evol 11:317-321

Siegrist C-A (2003) Mechanisms by which maternal antibodies influence infant vaccine responses: review of hypotheses and definition of main determinants. Vaccine 21:3406-3412

Silverstein AM (2001). Paul Ehrlich's receptor immunology: the magnificent obsession. Elsevier, Amsterdam.

Sin Y, Ling K, Lam T (1994) Passive transfer of protective immunity against ichthyophthiriasis from vaccinated mother to fry in tilapias, Oreochromis aureus. Aquaculture 120:229-237

Smale ST, Tarakhovsky A, Natoli G (2014) Chromatin contributions to the regulation of innate immunity. Annu Rev Immunol 32:489-511

Staszewski V, Siitari H (2010) Antibody injection in the egg yolk: maternal antibodies affect humoral immune response of the offspring. Funct Ecol 24:1333-1341

Stein LR, Bell AM (2014) Paternal programming in sticklebacks. Anim Behav 95:165-171

Sterken> MG, Snoek LB, Bosman KJ, Daamen J, Riksen JA, Bakker J et al. (2014) A heritable antiviral RNAi response limits Orsay virus infection in Caenorhabditis elegans N2. PLoS ONE 9: e89760

Stölting KN, Wilson AB (2007) Male pregnancy in seahorses and pipefish: beyond the mammalian model. Bioessays 29:884-896

Sunday JM, Bates AE, Dulvy NK (2012) Thermal tolerance and the global redistribution of animals. Nat Clim Chang 2:686

Swain P, Dash S, Bal J, Routray P, Sahoo P, Sahoo S et al. (2006) Passive transfer of maternal antibodies and their existence in eggs, larvae and fry of Indian major carp, Labeo rohita (Ham.). Fish Shellfish Immunol 20:519-527

Swain P, Nayak S (2009) Role of maternally derived immunity in fish. Fish Shellfish Immunol 27:89-99

Szyf M (2015) Nongenetic inheritance and transgenerational epigenetics. Trends Mol Med 21:134-144

Takemura A, Takano K (1997) Transfer of maternally-derived immunoglobulin (IgM) to larvae in tilapia, Oreochromis mossambicus. Fish Shellfish Immunol 7:355-363

Tate AT, Andolfatto P, Demuth JP, Graham AL (2017) The withinhost dynamics of infection in trans-generationally primed flour beetles. Mol Ecol 26:3794-3807

Tate AT, Graham AL (2015) Trans-generational priming of resistance in wild flour beetles reflects the primed phenotypes of laboratory populations and is inhibited by co-infection with a common parasite. Funct Ecol 29:1059-1069

Tidbury HJ, Best A, Boots M (2012) The epidemiological consequences of immune priming. Proc Biol Sci 279:4505-4512

Trauer-Kizilelma U, Hilker M (2015) Insect parents improve the antiparasitic and anti-bacterial defence of their offspring by priming 
the expression of immune-relevant genes. Insect Biochem Mol Biol 64:91-99

Vantaux A, Dabiré KR, Cohuet A, Lefèvre T (2014) A heavy legacy: offspring of malaria-infected mosquitoes show reduced disease resistance. Malar J 13:442

von Schantz T, Bensch S, Grahn M, Hasselquist D, Wittzell H (1999) Good genes, oxidative stress and condition-dependent sexual signals. Proc Biol Sci 266:1-12

Voordouw MJ, Lambrechts L, Koella J (2008) No maternal effects after stimulation of the melanization response in the yellow fever mosquito Aedes aegypti. Oikos 117:1269-1279

Vorburger C, Gegenschatz SE, Ranieri G, Rodriguez P (2008) Limited scope for maternal effects in aphid defence against parasitoids. Ecol Entomol 33:189-196

Wade PA, Pruss D, Wolffe AP (1997) Histone acetylation: chromatin in action. Trends Biochem Sci 22:128-132

Walke JB, Harris RN, Reinert LK, Rollins-Smith LA, Woodhams DC (2011) Social immunity in amphibians: evidence for vertical transmission of innate defenses. Biotropica 43:396-400

Wassarman PM, Jovine L, Litscher ES (2001) A profile of fertilization in mammals. Nat Cell Biol 3:E59

Watanaveeradej V, Endy TP, Samakoses R, Kerdpanich A, Simasathien S, Polprasert N et al. (2003) Transplacentally transferred maternal-infant antibodies to dengue virus. Am J Trop Med Hyg 69:123-128

Watson FL, Püttmann-Holgado R, Thomas F, Lamar DL, Hughes M, Kondo $\mathrm{M}$ et al. (2005) Extensive diversity of Ig-superfamily proteins in the immune system of insects. Science 309:1874-1878
Wilson AB, Vincent A, Ahnesjö I, Meyer A (2001) Male pregnancy in seahorses and pipefishes (family Syngnathidae): rapid diversification of paternal brood pouch morphology inferred from a molecular phylogeny. J Hered 92:159-166

Wolf JB, Brodie ED (1998) The coadaptation of parental and offspring characters. Evolution 52:299-308

Wourms JP, Lombardi J (1992) Reflections on the evolution of piscine viviparity. Am Zool 32:276-293

Xiao C, Rajewsky K (2009) MicroRNA control in the immune system: basic principles. Cell 136:26-36

Youngblood B, Hale JS, Ahmed R (2015) Memory CD8 T cell transcriptional plasticity. F1000Prime Rep 7:38

Youngson NA, Whitelaw E (2008) Transgenerational epigenetic effects. Annu Rev Genom Hum Genet 9:233-257

Yue F, Zhou Z, Wang L, Ma Z, Wang J, Wang M et al. (2013) Maternal transfer of immunity in scallop Chlamys farreri and its trans-generational immune protection to offspring against bacterial challenge. Dev Comp Immunol 41:569-577

Zanchi C, Troussard JP, Martinaud G, Moreau J, Moret Y (2011) Differential expression and costs between maternally and paternally derived immune priming for offspring in an insect. J Anim Ecol 80:1174-1183

Zhang S, Wang Z, Wang H (2013) Maternal immunity in fish. Dev Comp Immunol 39:72-78

Zhang Y, Reinberg D (2001) Transcription regulation by histone methylation: interplay between different covalent modifications of the core histone tails. Genes Dev 15:2343-2360 